
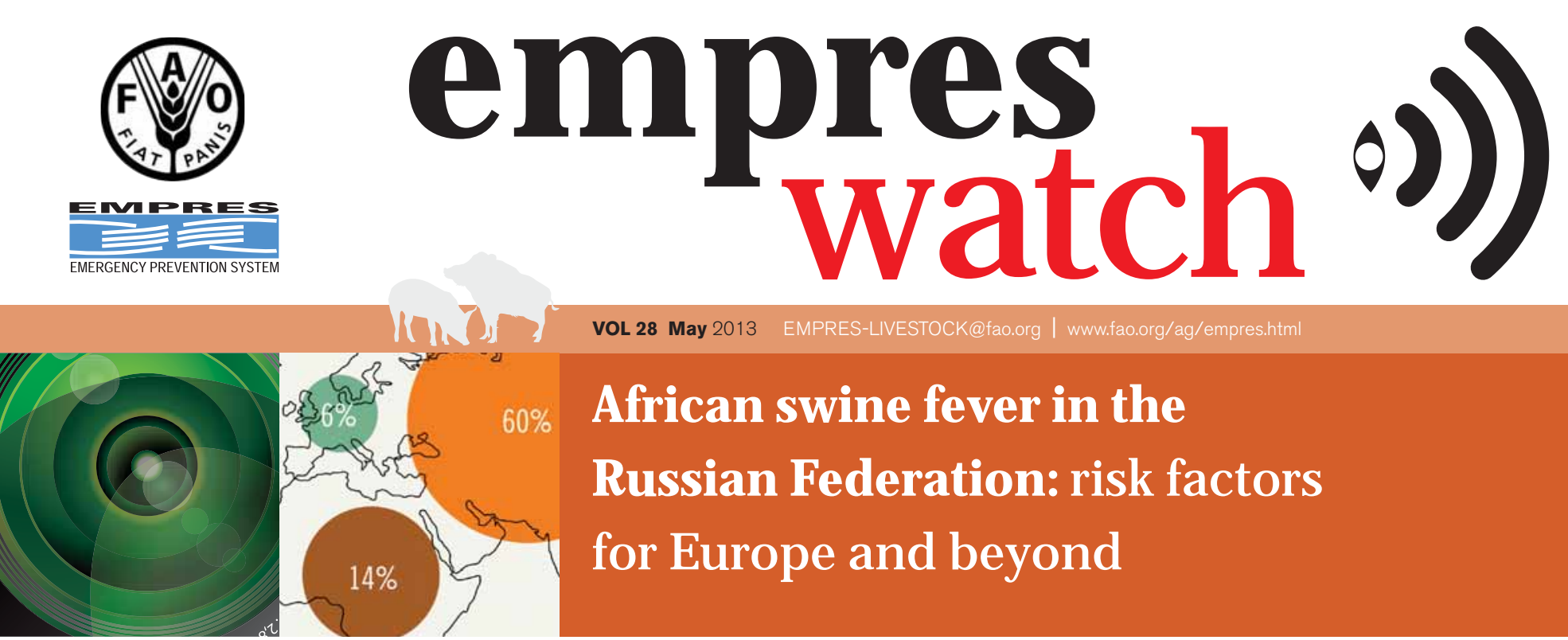

VOL 28 May 2013 EMPRES-LIVESTOCK@fao.org | www.fao.org/ag/empres.html

\title{
African swine fever in the
}

\section{Russian Federation: risk factors}

for Europe and beyond

Contributors: Sergei Khomenko ${ }^{a}$, Daniel Beltrán-Alcrudo ${ }^{a}$, Andriy Rozstalnyy ${ }^{a}$, Andrey Gogin ${ }^{b}$, Denis Kolbasov ${ }^{b}$, Julio Pinto ${ }^{a}$, Juan Lubroth ${ }^{a}$, Vincent Martin ${ }^{a}$

a Food and Agriculture Organization of the United Nations (FAO)

${ }^{b}$ All-Russian Scientific Research Institute of Veterinary Virology and Microbiology (Pokrov, Russian Federation)

\section{Contents}

\section{Introduction}

\section{Overview on key production \\ systems affected by ASF}

\section{ASF main epidemiological}

\section{features}

\section{Challenges in ASF detection and control}

\section{Risk assessment for}

$$
\text { the region }
$$

\section{Risk management options}

\section{for at-risk countries}

\section{Conclusions}

References

\section{Introduction}

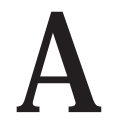

frican swine fever (ASF) is one of the most severe viral pig diseases. Some genotypes can cause up to 100 percent mortality in pigs and wild boar, such as the genotype II virus introduced into Georgia in 2007 (Chapman et al., 2011), which spread throughout the Caucasus (Beltran-Alcrudo et al., 2008) into the Islamic Republic of Iran (Rahimi et al., 2010), the Russian Federation (BeltranAlcrudo et al., 2009) and, in July 2012, into
Ukraine (Dietze et al., 2012). Without the availability of effective vaccines or treatment, outbreaks of ASF have been controlled in some countries by stamping out and through the implementation of strict movement bans of swine and their products. However, these measures are difficult to implement unless the veterinary services are well-equipped, have reliable, trained personnel and sufficient and timely access to funds (for operations and adequate compensation). In addition, extensive culling implies economic losses and shortfalls in available food, particularly for the poorest farmers and households. One of the most important challenge is to get the outbreaks reported by the farmers.

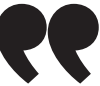

GIVEN THE WORRISOME DEVELOPMENTS IN THE RUSSIAN FEDERATION, EUROPEAN COUNTRIES HAVE TO BE ALERT AND READY TO PREVENT AND TO REACT EFFECTIVELY TO ASF INTRODUCTIONS INTO THEIR TERRITORIES FOR MANY YEARS TO COME.

\section{In the Russian Federation, ASF has} persisted since 2008 and continues to spread. The disease is endemic in most of the south and is on its way to becoming endemic in Tverskaya Oblast, not far from Moscow, where some of the highest pig and wild boar densities are found. Over 600000 pigs have died or have been culled from 2007 to mid2012 due to ASF. Overall losses, including indirect ones, were estimated at around 30 billion roubles or US\$1 billion (Anonymous, 2012).

Since 2008, the Food and Agriculture Organization of the United Nations (FAO) has repeatedly warned of the high risk of ASF spreading to neighboring countries and the likelihood that it will then establish in these newly infected areas (Beltran-Alcrudo et al., 2008 and 2009; FAO, 2010; Dietze et al., 2012). Such developments could lead to the expansion of ASF into Eastern Europe and beyond.

The analysis of the situation in the Russian Federation and its production and marketing systems here presented, allows us to better understand the epidemiology and spread patterns of the disease in the region, and to identify critical areas for improved disease management. FAO, in collaboration with the All-Russian Scientific Research Institute of Veterinary Virology and Microbiology (National Reference Laboratory on ASF) in Pokrov, has prepared a comprehensive overview on the subject. This technical publication is based largely on those findings. The knowledge provided here will better inform veterinary services, animal health professionals, pig producers and decision-makers in Europe, and in other countries around the globe.

Countries immediately bordering the Russian Federation, particularly Ukraine, Republic of Moldova, Kazakhstan and Latvia, are most vulnerable to ASF introduction and endemic establishment, largely because the biosecurity of their pig sector is predominantly low. The prevention of ASF spread into Ukraine is particularly critical for the whole pig production sector in Europe. Given the worrisome developments in the Russian Federation, European countries have to be alert. They must be ready to prevent and to react effectively to ASF introductions into their territories for many years to come. 
Figure 1. Yearly detections of ASFV in the Russian Federation shown separately for wild boar (left) and domestic pigs (right) from 14 November 2007 to 29 December 2012.

Figures in parenthesis next to the year represent the number of outbreaks or virus detections in meat/carcasses. Crossed circle indicates the first known incursion of ASF into the Russian Federation. The only outbreak of ASF (31 July 2012) in Ukraine is also shown.
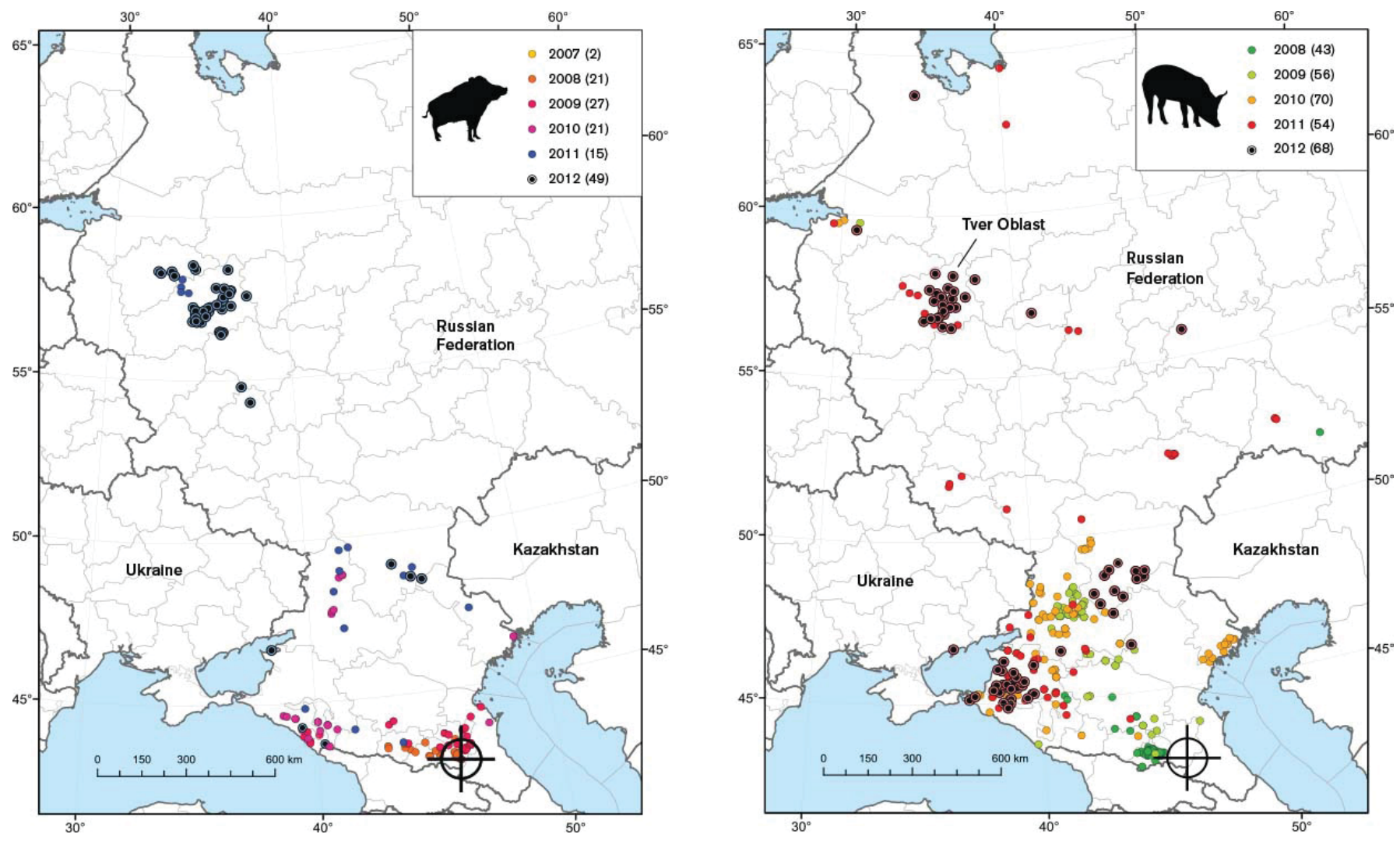

\section{Overview on key production systems affected by ASF}

\section{Pig production systems}

Pig production in the Russian Federation meets only 63.8 percent of the domestic pork demand (as of 2010). In 2009, 85.4 percent of the 17.2 million pigs in the country were concentrated in four federal districts: the Central (28.8 percent), the Volga (25.4 percent), the Siberian (17.2 percent) and the Southern (14.0 percent), with pig densities higher than 4 animals $/ \mathrm{km}^{2}$. The remaining four federal districts (the Urals, the North Western, the North Caucasian and the Far Eastern) accounted for only 14.6 percent of the national herd with just a few regions where pig density exceeds 4 animals $/ \mathrm{km}^{2}$ (Figs. 2 and 3). Some free-range production is practised seasonally in North Ossetia Alania and parts of the North Caucasian and Southern federal districts.

According to biosecurity standards, pig production systems of the Russian Federation can be divided into three main categories: a) specialized (industrial) production units with generally high biosecurity (HB) (61 percent of the total population); b) small commercial farms (5 percent); and c) backyard subsistence production (34 percent). The last two categories have typically low to non-existent biosecurity and will be hereafter referred to as the low biosecurity (LB) sector. These LB sectors are generally more susceptible to incursions of ASF and other pathogens. In terms of population size, particularly with regard to backyard pigs, the LB sector is comparable to the HB sector in many parts of the Russian Federation, and is larger than the HB sector in some areas (Figs. 2 and 3). The geographical distribution of the LB sector $(b+c)$ is depicted in Figure 2.

In the Russian Federation, the LB production systems do not receive or have access to much institutional support to deal with animal diseases. Moreover, disease prevention and control is most challenging in these settings due to a number of factors, including: lower levels of awareness and biosecurity, poor compliance to livestock related regulations (reporting, movement control, certifications and inspection, vaccination, etc.) and lack of animal identification and traceability.

\section{Wild boar distribution and numbers}

In the European part of the Russian Federation, where outbreaks of ASF have been reported from 2007 to 2012, wild boar populations are distributed continuously across space. However, wild boar population density is relatively low and only seldom exceeds 0.43 heads $/ \mathrm{km}^{2}$ even in the forested areas, where numbers are highest (Fig. 4). According to official data (Volodina, 2011), in 2010, wild boar numbers in the Russian Federation reached their highest levels in 30 years (404 400 heads). However, in most areas, the rapid growth of wild boar populations observed in the last eight years (inserted graph in Fig. 4) appears to be leveling off. One third of the wild boar population (129 400) is concentrated in the Central Federal District, followed by Volga ( 85 400) and Siberian (53 500) federal districts. These three districts account for 66.3 percent of the national wild boar population.

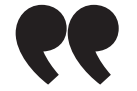

THE IMPLEMENTATION OF DISEASE CONTROL MEASURES IN WILD BOAR IS COMPLICATED BY THE CONFLICT OF INTEREST BETWEEN DIFFERENT STAKEHOLDERS, GAPS IN LEGISLATION AND LOGISTICAL CHALLENGES IN IMPLEMENTING SURVEILLANCE AND CONTROL.

Over most of their range in the Russian Federation, wild boar are sedentary and highly territorial. However, some populations show certain degrees of mobility, such as seasonal vertical migrations into the mountains 
(Caucasus, Altai), or seasonal movements in semi-arid areas (southern Russian Federation, Kazakhstan) and at the extreme north of its distribution range in the northwest of the Russian Federation (Sludskiy, 1956; Danilkin, 2002). Critical weather events, natural disasters (floods, fires) as well as direct encroachment and hunting by man, can stimulate unprecedented movements of animals, too, and in an unpredictable manner.

The issues of wild boar health status control and population management become increasingly relevant with the recent expansion of ASF into temperate forests of European Russia. The implementation of disease control measures in wild boar is complicated by the conflict of interest between different stakeholders, gaps in legislation and logistical challenges in implementing surveillance and control.

\section{ASF main epidemiological features}

\section{Descriptive analysis of the 2007-2012 epidemic}

ASF was introduced in the Russian

Federation in November 2007, most likely through movements of infected wild boar from Georgia to the Chechen Republic. The following year, ASF spread rapidly into six new administrative areas of the Russian Federation. Initially, infection was limited to wild boar (Chechen and Ingush Republics, Figs. 1 and 2) and the free-range pig production systems (North Ossetia), but after 2008, it expanded to all pig production sectors, particularly the backyard sector. During 2009 and 2010, ASF progressively established itself in the south of the Russian Federation with a few occasional introductions outside this area. In 2011 to 2012 , the disease spread rapidly to new areas in the north. Currently, the role of wild boar in disease spread seems to be secondary. As a result of spillover infections from domestic pigs, they act as sentinels of the presence of the disease. Outside of the Caucasus region, the infection in wild boar goes hand in hand with outbreaks in domestic pigs (Fig. 1, see account on epidemiology).

By the end of 2012, there were a total 426 ASF detections in the Russian Federation since the beginning of the epidemic. From 2008 to 2012 , the country reported an average of 58 (43-68) ASF detections in domestic pigs and 27 (15-49) cases in wild

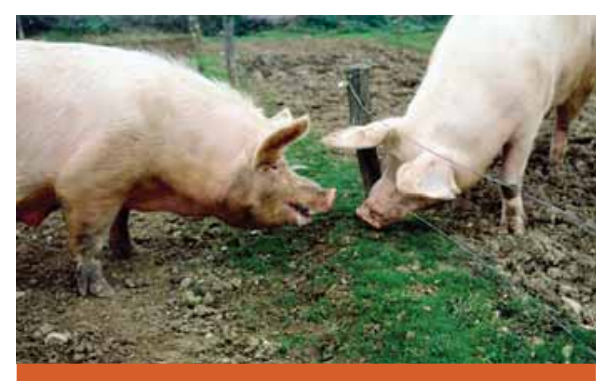

(C) FAO

boar, annually. Epidemiological trends do not indicate improvement, and the disease has been endemic in the southern part of the country for several years.

The epidemiological situation in and around Tver Oblast (Fig. 1) is particularly worrisome. After the original detection of the disease in backyard pigs in April 2011, the virus fatally infected wild boar multiple times: four times throughout the rest of 2011; and 25 times from January to August 2012. In June to August 2012, 22 ASF outbreaks in domestic pigs (including several large specialized farms) were reported again, suggesting the existence of an endemic cycle. The ASF progressive geographical expansion in the region also involves Novgorod (in wild boar), Yaroslavl (in domestic pigs) and

Figure 2. Proportion (A) and density (B) of pig population in low biosecurity sectors $(b+c)$ in the Russian Federation.

The Table on the right summarizes the yearly ASF occurrence in 2007-2012 (at the second level of administrative division of the

Russian Federation) for wild boar and domestic pigs in chronological order. Data: Federal State Statistics Service (FSSS), 2009.

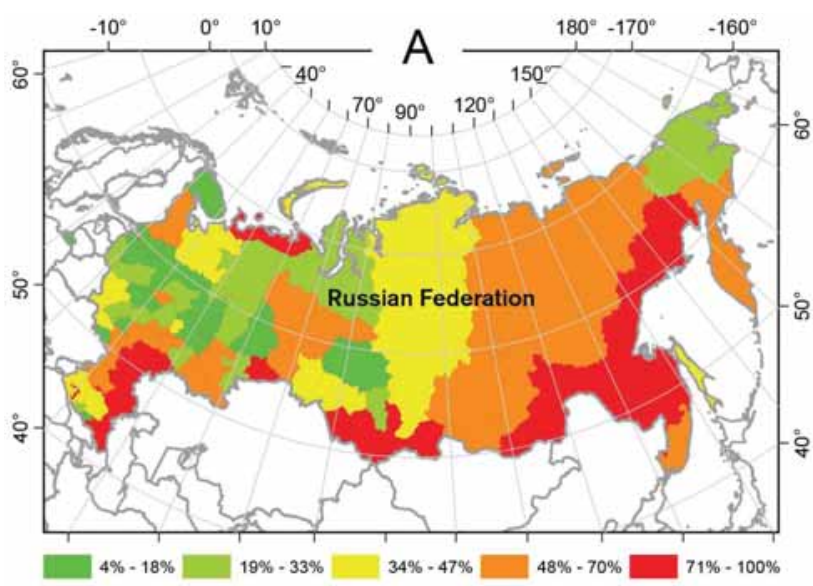

\section{REGION}

1 CHECHEN 2 INGUSH

3 KRASNODAR

4 ORENBURG

5 N OSETIA-ALANIA

6 STAVROPOL

7 LENINGRAD

8 DAGESTAN

9 KALMYKIYA

10 ROSTOV

11 ASTRAKHAN

12 VOLOGDA

13 ST. PETERSBURG

14 ADYGEYA

15 KABARDINO-BALKAR

16 KARACHA-CHERKES

17 ARKHANGELSK

18 VORONEZH

19 KURSK

20 MURMANSK

21 NIZH. NOVGOROD

22 SARATOV

23 TVER

24 KARELIA

25 NOVGOROD

26 TULA

27 YROSLAVL.

28 IVANOVO

29 MOSCOW

30 TATARSTAN

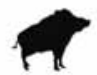

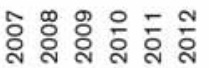

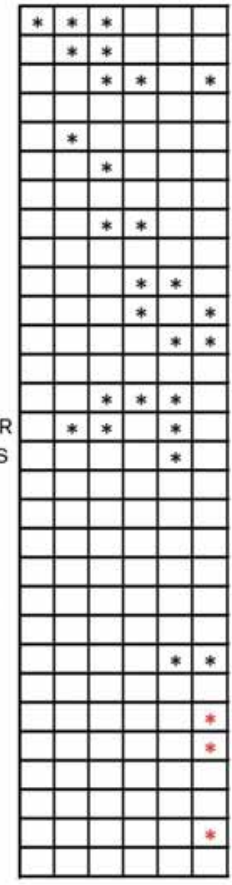

* endemic or sporadic

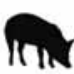

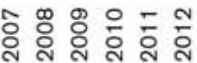

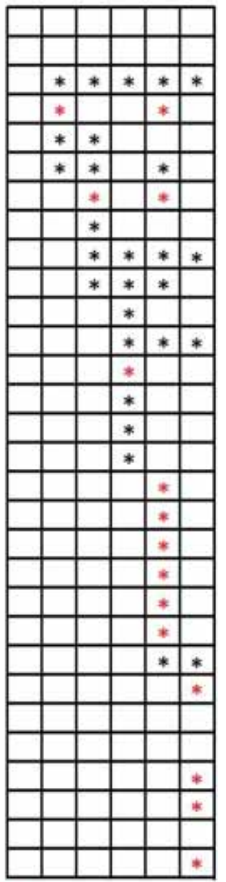

* single introductions 
Figure 3. Pig population (in thousands) and sector classification (where $A=$ industrial production units; $B=$ small commercial and small farms; and $\mathrm{C}=$ backyard production) by federal districts of the Russian Federation ordered by total pig population sizes. Data: FSSS, 2009.

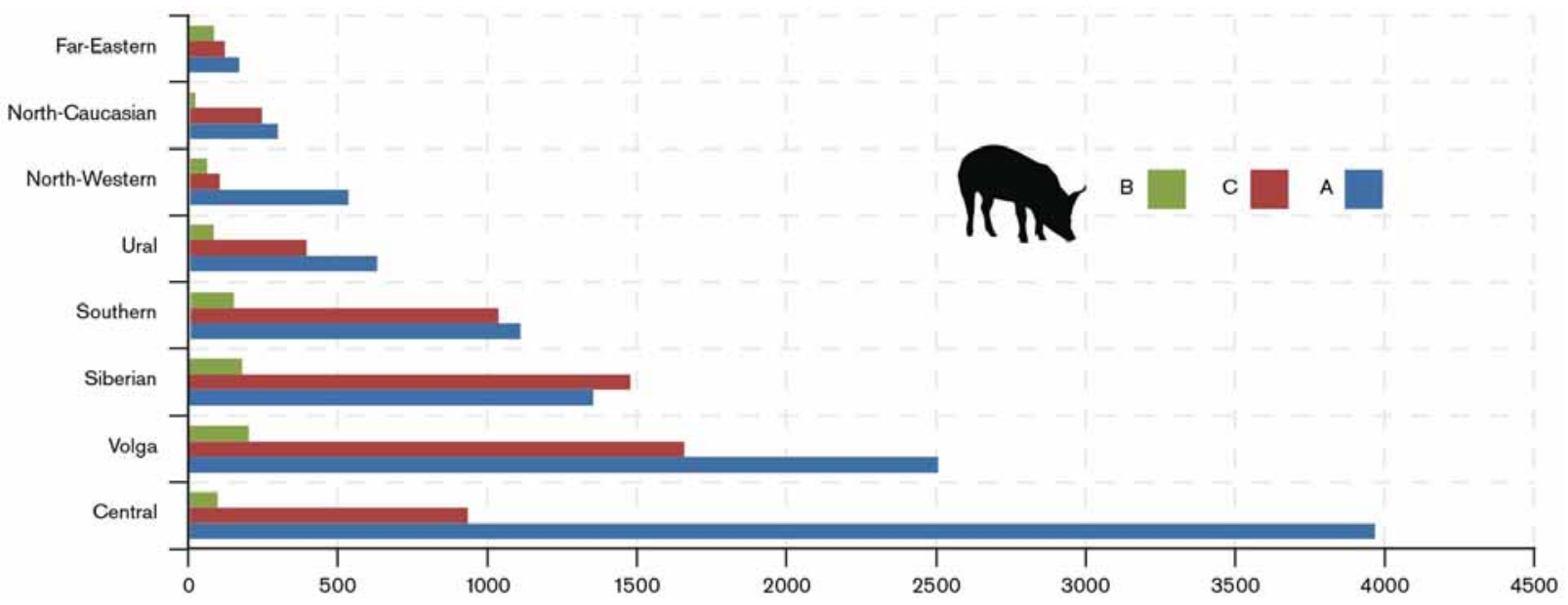

Figure 4. Wild boar density in 2010.

Data: numbers 2003-2010 in the Russian Federation (Volodina, 2011); range represented as shaded areas (Saulich, 2007). Note that density is per total area of the administrative unit classified by the method of quintiles without accounting for actual distribution range. \begin{tabular}{c|c|c|c|} 
heads / km sq & $\square$ \\
\hline$<0.02$ & $0.02 \cdot 0.04$ & $0.08 \cdot 0.10$ & $0.19 \cdot 0.31$ \\
& $0.05 \cdot 0.07$ & $0.11 \cdot 0.18$ & $0.32 \cdot 0.44$
\end{tabular}
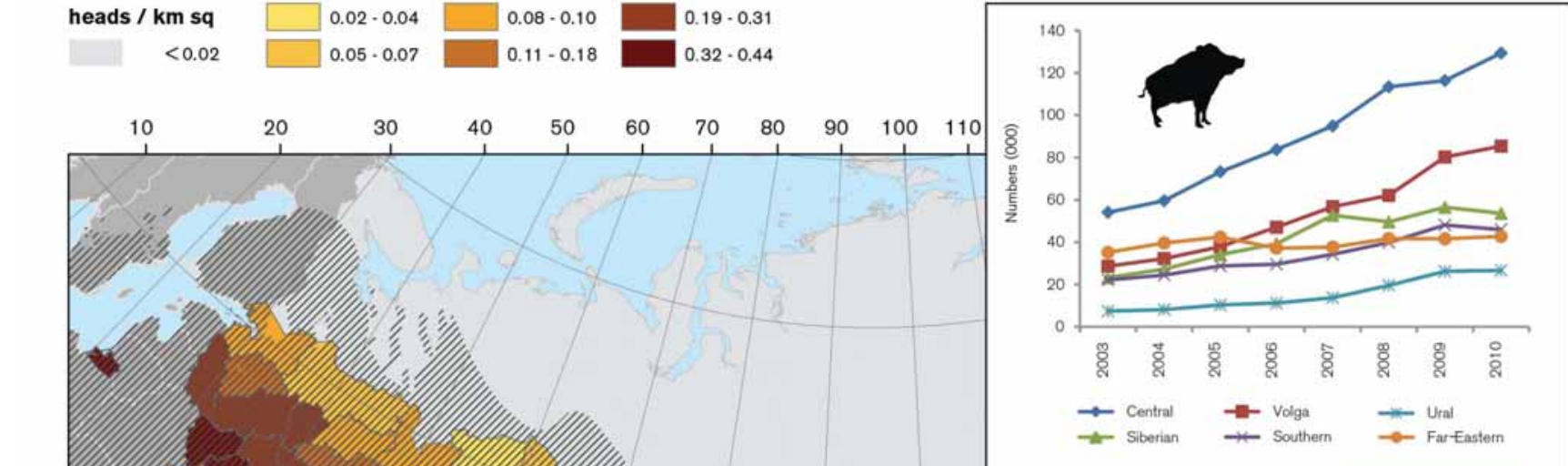

50

40

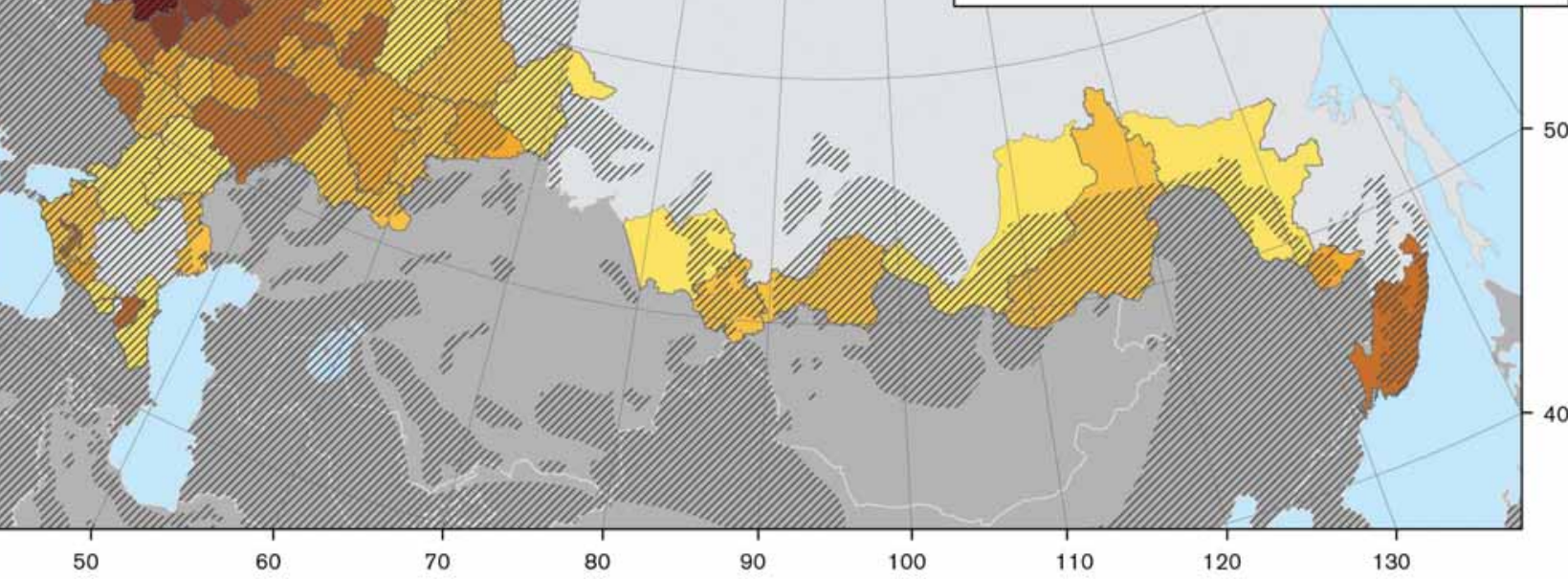

$250 \quad 500 \quad 1000 \mathrm{~km}$

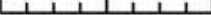

Moscow Oblasts. The high number of wild boar outbreaks in the area with the highest density in the Russian Federation (Figs. 1 and 4) may mark the beginning of a new epidemic pattern, with the potential yearround transmission in wild boar at temperate latitudes. Should it become the case, the continuous wild boar distribution in Eastern and Central Europe may provide the perfect path for ASF spread into the European Union (EU) and its 3.5 million wild boar (Putmen et al., 2011). The high wild boar densities in
Central Europe would make ASF eradication considerably difficult.

The areas where ASFV has been detected can be classified into three categories: endemic (ASF reported $\geq 3$ years), sporadic (ASF reported for 2 consecutive years) and 


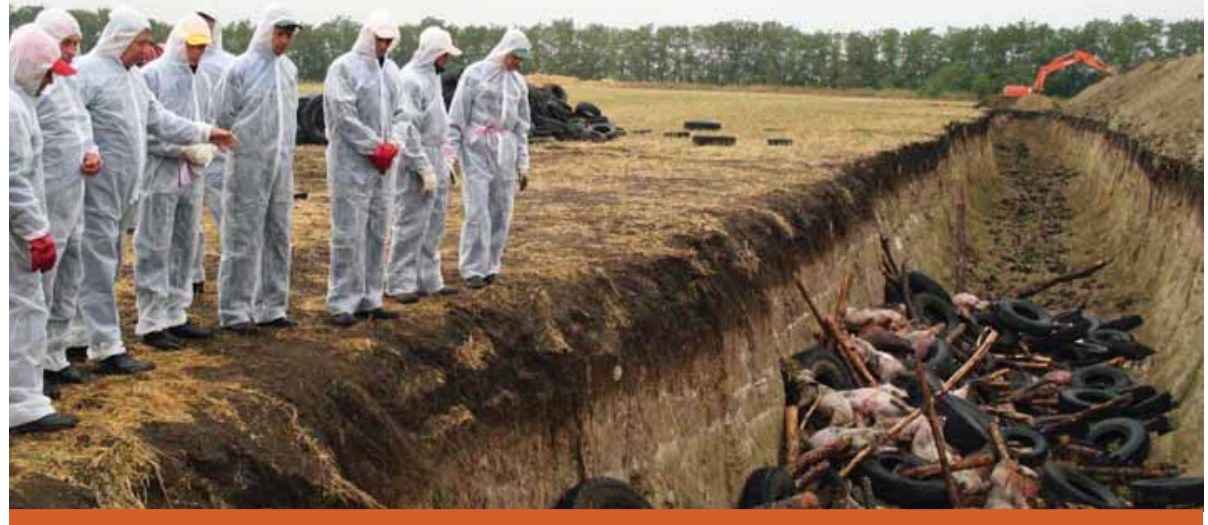

Carcasses of pigs prepared to be destroyed by burning as a part of disease control measures at an ASF outbreak site in the Russian Federation. (c) Andrey Gogin

occasional introductions (single detections of ASF with no secondary spread). The whole of the North Caucasian and Southern Federal districts can be considered ASF endemic (roughly below $50^{\circ} \mathrm{N}$ ), although the disease was not recorded in every oblast for three years. So far, outside of the endemic zone, ASF occurred sporadically in Astrakhan and Tver Oblasts. Everywhere else (15 out of 30 administrative units affected), ASF occurred only occasionally with no or only limited local spread (Fig. 2, right side Table, highlighted in red).

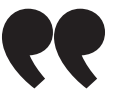

THE HIGH NUMBER OF WILD BOAR OUTBREAKS IN TVER, THE AREA WITH THE HIGHEST DENSITY IN THE

Russian FEDERATION, MAY MARK THE BEGINNING OF A NEW EPIDEMIC PATTERN, WITH THE POTENTIAL YEAR-ROUND TRANSMISSION IN WILD BOAR AT TEMPERATE LATITUDES.

An analysis of all ASF outbreaks until mid-2012, revealed that most outbreaks were reported in the backyard pig production sector (37 percent), followed by cases in wild boar (29 percent), outbreaks on specialized pig production units (16 percent), detections of the virus in infected objects ( 9 percent) and outbreaks on small farms (7 percent). Infected objects $(n=31)$ refer to illegally disposed carcasses (61.3 percent), slaughterhouses or meat processing plants (22.6 percent) and other (16.1 percent). ASF activity in 2012 reached its maximum since the beginning of the epidemic with 121 detections (61 in pigs, 45 in wild boar and 15 infected objects).

Considering that 44.3 percent of the susceptible population is kept in the backyard sector (compared to 49 percent in specialized farms, 5.5 percent in small farms and 1.3 percent wild boar), and the small size of backyard herds (usually under ten pigs), we can conclude that well over 90 percent of ASF-susceptible epidemiological units are backyard holdings. However, despite the high susceptibility of those holdings due to low biosecurity, the backyard sector only reports 41.6 percent of outbreaks, thus suggesting that outbreaks in this sector are grossly under-reported. This statistic implies that a large proportion of infected animals will end up being illegally disposed of or slaughtered and sold. Inefficient disease control efforts and compensation strategies are to blame. Moreover, this under-reporting in the backyard sector seems to be increasing as the epidemic evolves. In 2008 and 2009 ( $n=$ 116), small backyard holdings (1-5 heads), medium-sized farms (<1000 heads) and large farms ( $>1000$ heads) were affected in the proportion $83: 11: 6$, which changed to nearly equal ratios of 35:34:31 in 2012 ( $n=$ 68). These figures also suggest an increasing risk of infection in medium and large farms, as ASF progressively establishes and spreads in the LB sector. This shift can be partially explained by considering that in the Russian Federation, unlike in Ukraine or Belarus (FAO, 2010), LB and HB farms are not spatially segregated. This shift of disease to commercial units implies a dramatic increase in the number of slaughtered animals, and consequent economic losses. In wild boar, on the other hand, most outbreaks seem to be detected (based on the total number of ASFaffected animals) and readily reported (32.8 percent of outbreaks and only 1.3 percent of the susceptible population).

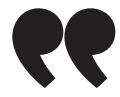

THE SOURCE OF INFECTION IN PRIMARY OUTBREAKS IS MOSTLY THROUGH CONTAMINATED SWILL.

The route of ASF introduction into new pig populations (primary outbreaks) remains unidentified in 28.3 percent of cases (45 out of 159). The source of infection is mostly through contaminated swill (97 percent of all the identified sources of infection, $n=$ 109) and rarely through contact with wild boar (2 percent; exclusively in North Ossetia) or fomites such as contaminated vehicles (1 percent). The route of secondary spread remains unidentified in $\mathbf{5 8 . 1}$ percent of cases (25 out of 43). When identified, spread usually occurs through contaminated vehicles (62.1 percent), direct contact with pigs or people from holdings nearby (33.3 percent), or through the introduction of new pigs in the herd during the incubation period (5.6 percent).

\section{Seasonality}

Overall, ASF in the Russian Federation is particularly active during the main backyard pig production season, with three-quarters of all ASF events reported from June through November; the peak incidence in October (17.4 percent) and the minimum disease activity in April (Fig. 5). In the backyard sector alone, the virus is most active in July (18.8 percent) and October (22.4 percent), with the majority of outbreaks (44.6 percent) taking place in summer. Seasonal patterns observed both in the small farms and specialized sectors, are similar to each other and to the backyard sector, though outbreaks in these two sectors are delayed by one month and biased towards the period from September to November. These three months account for 45.7 percent of all outbreaks on farms. ASF incidence in wild boar stays high from November through February (43 percent), with a maximum in December (14 percent). It peaks again in May (15 percent) and June (9 percent). These two months account for one quarter of all wild boar outbreaks. In pork (and other pig by-products) and illegally disposed carcasses, ASFV is most often found in September (21.4 percent) and October (32.1 percent) with a secondary peak in December (17.1 percent). Interestingly, the seasonal ASF incidence in wild boar is negatively correlated with that of all domestic pigs, as well as with backyard pigs (Pearson's $r=-0.70$ and -0.68 , respectively; $p=0.01$; degrees of freedom $-d f=10)$. Contrary to this result, ASF seasonality in small and specialized farms was positively correlated with that of the backyard sector ( $r=0.65$ and 0.59 , respectively; $p<0.05)$. The specialized sector shows a better fit with the seasonality in the backyard sector $(r=0.66, p=0.02, d f=8)$ once lagged by one month, suggesting that infection arrives at higher biosecurity holdings with a one-month delay. Seasonality in the detection of the ASF-infected objects correlates well only with that of small farms $(r=0.6, p=0.03$, $\mathrm{df}=8$ ), suggesting that these carcasses, pork and other pig by-products originate mainly from those holdings.

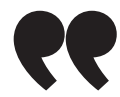

Overall, ASF In the Russian Federation IS PARTICULARLY ACTIVE DURING THE MAIN BACKYARD PIG PRODUCTION SEASON, WITH THREE-QUARTERS OF ALL ASF EVENTS REPORTED FROM JUNE THROUGH NOVEMBER.

\section{Domestic cycle}

The LB production systems (backyard and small farms) represent the main epidemiological reservoir of ASFV in 
the Russian Federation. These holdings commonly use swill as supplementary feed, often including untreated ASF-contaminated pork or pig products. Often, the infected meat may have been stored chilled, frozen or after treatment and kept over long periods of time, thus acting as the true ASFV reservoir, since low temperatures and some non-heat treatments do not inactivate the virus. Virus introduction and amplification mainly takes place in the backyard pigs and then ASF seasonally spills over first to small farms and then to the specialized pig farms.

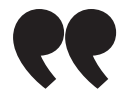

THE LOW BIOSECURITY PRODUCTION SYSTEMS REPRESENT THE MAIN EPIDEMIOLOGICAL RESERVOIR OF ASFV IN THE RUSSIAN FEDERATION.

The lowest ASF incidence is observed from December through May, when most adult pigs in the LB sector have been slaughtered for the Christmas celebrations and the remaining population consists mainly of sucking piglets. Once the disease is introduced in the LB sector, its prevalence starts to increase towards the middle of the production season (June to August), when pig population density and activities both increase. It seems that the early cases in juvenile pigs (April to May) go under-reported and are disposed of into the environment, which would explain the spring peak in wild boar ASF incidence. The further increase in virus load results in a higher involvement of all pig production sectors: first, the backyard and small farms and then, the specialized farms. This involvement leads to the second seasonal peak in ASF incidence (October to November), with between farm $R_{0}$ ranging between two and three (Gulenkin et al., 2011). This results in the massive disposal of infected carcasses into the environment and the distribution of infected meat through the informal market chains. The LB sector is the primary source of illegally disposed contaminated carcasses (particularly backyard) and contaminated pork and other pig by-products (mainly small farms). The incentive for selling the meat, rather than disposing of carcasses or reporting the disease, grows together with the weight (and market value) of pigs, which is greatest at the end of the production cycle (December).

\section{Catering cycle}

The ASF-infected meat (including frozen or salted products) enters the market at the time when seasonal pork offer is high (November to February). Infected pig products may then be distributed outside affected (quarantined and trade restricted) areas, travelling large distances (thousands of $\mathrm{km}$ ) within the country, particularly to pig-deficient areas, usually found further north. Over 20 such long-distance jumps were recorded

Figure 5. . Seasonality of ASF events in the Russian Federation from November 2007 to June 2012 corrected for $\boldsymbol{n}$ of observation months.

A) months above the expected average incidence (8.3 percent) in all domestic pigs, wild boar and infected objects; B) Overall seasonality of all virus detections $(n=330) ; C)$ Outbreaks in backyard pigs ( $n=122)$; D) Outbreaks in wild boar $(n=96)$; E) Outbreaks on large $(n=51)$ and small $(n=24)$ farms; F) ASFV detections on infected objects $(n=31)$. Figures in red are the average monthly incidences in percent.

A Infected objects - Wild boar = Domestic pigs -
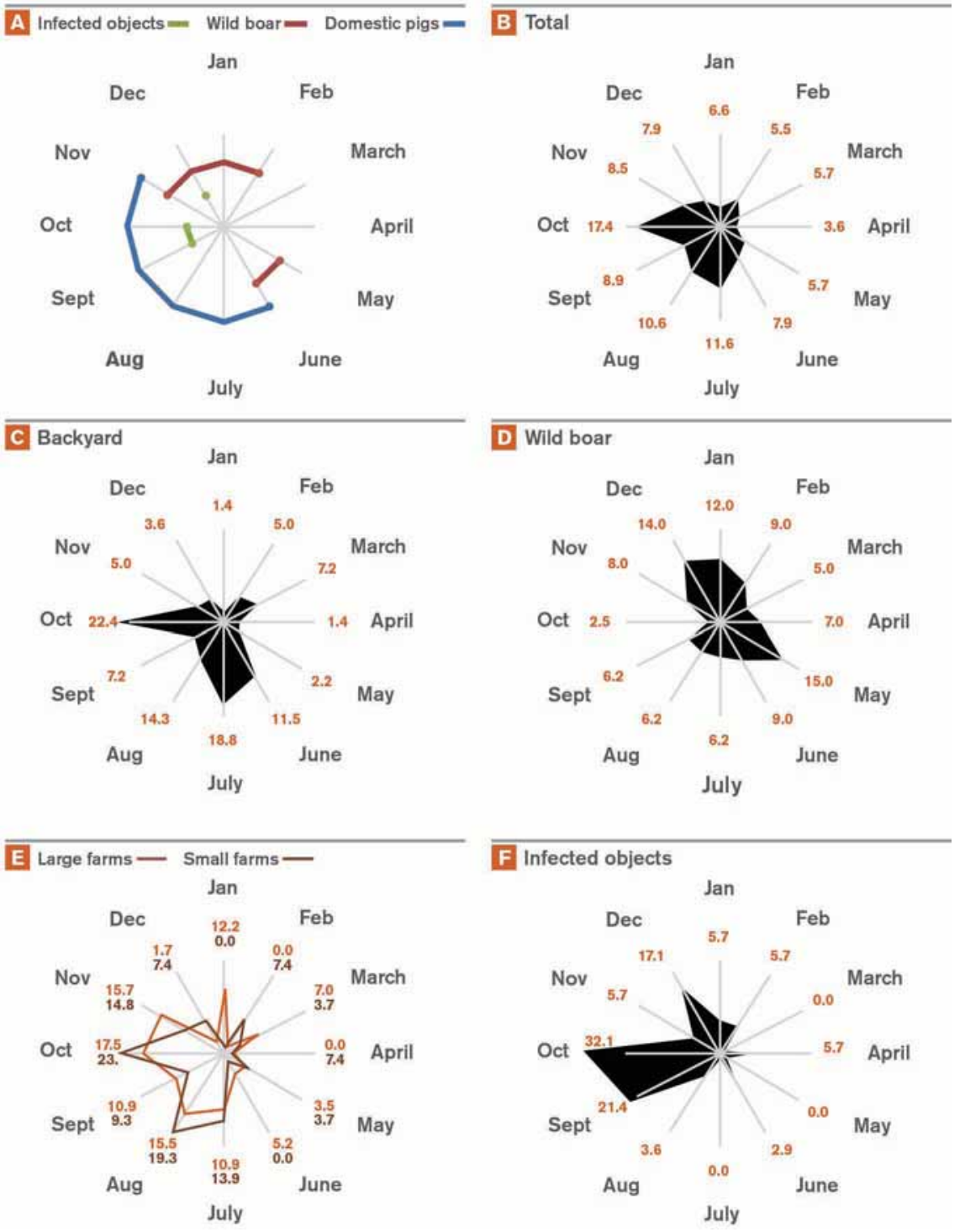

(Dudnikov et al., 2011). Wholesale buyers, particularly the military food supply system, have been implicated multiple times in the illegal distribution of contaminated meat, e.g. the repeated outbreaks in Leningrad Oblast. During the winter season, ASF incidence in the backyard sector strongly declines due to low pig populations, while the "catering cycle" gains priority towards the beginning of spring. As the meat procured in autumn and stored through the winter gets gradually consumed (swill fed to pigs), small subsistence urban farms established close to the source of abundant food leftovers (army canteens and catering facilities, prisons or educational institutions, which are mainly found in urban areas) are affected. Out of 14 ASF cases reported outside of the endemic zone, 10 (71 percent) took place during the months of
March through July (Dudnikov et al., 2011). Epidemiological investigations reveal that in all such cases the source of infection was related to swill feeding. The urban farms act as sentinels, most clearly demonstrating the wide geographical reach of the illegal trade in contaminated pork in the Russian Federation.

\section{ASF in wild boar}

Wild boar experience 27 percent of all reported outbreaks of ASF. Usually, infection begins when wild boar populations scavenge on illegally disposed ASF-infected pig carcasses from the domestic sector. The timing of carcass disposal into the environment coincides with the arrival of negative temperatures and snow (October) in forested areas. At this time, wild boar gather at the places where supplementary food is 
Figure 6. Transmission cycles of African swine fever in the Russian Federation involving low biosecurity pig production systems and wild boar.

Solid arrows indicate the main transmission routes as revealed by epidemiological investigations.

Dotted arrows are suspected transmission pathways.

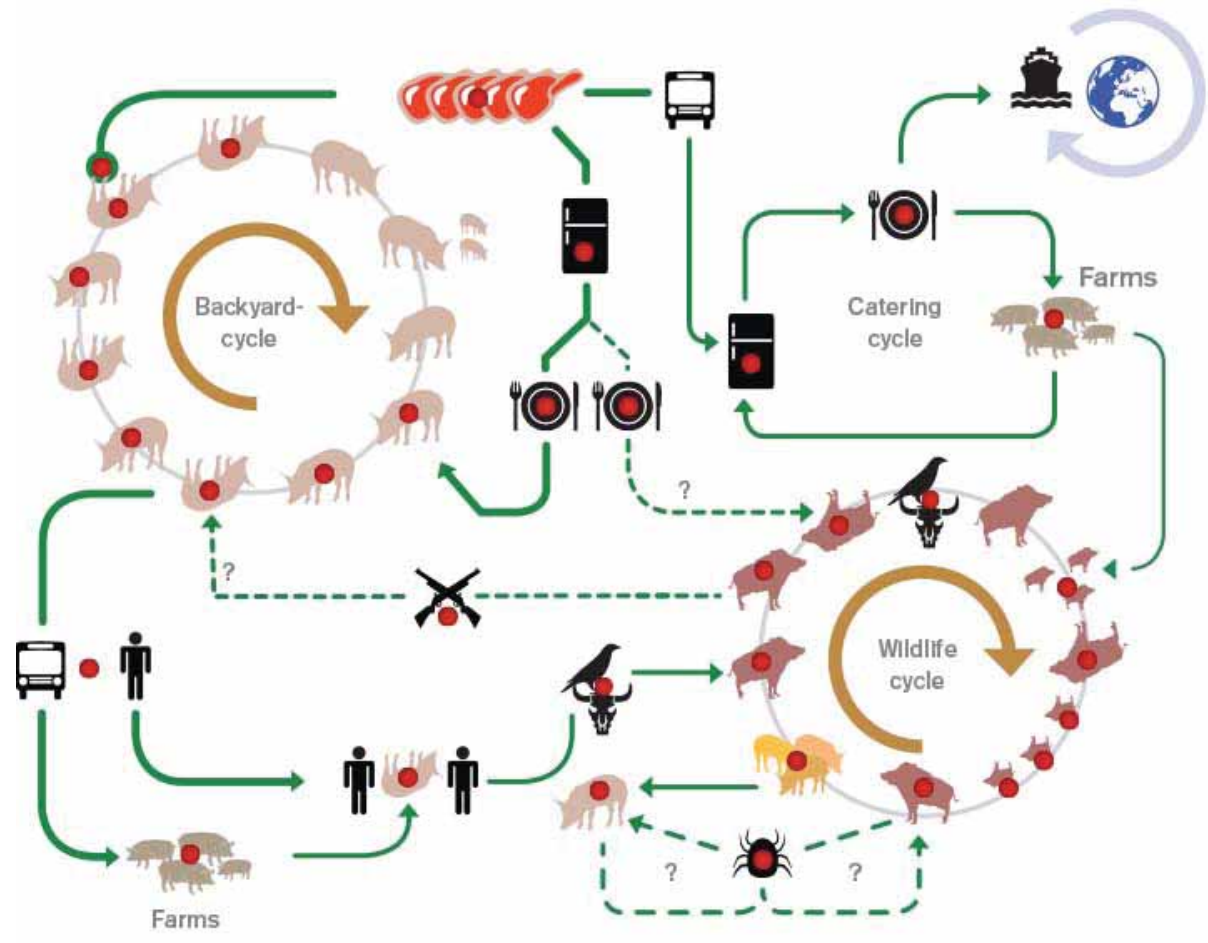

\begin{tabular}{|c|c|}
\hline & Legend \\
\hline 0 & Infection \\
\hline & Small feeding \\
\hline & Local transport \\
\hline & $\begin{array}{l}\text { Long-term } \\
\text { meat storage }\end{array}$ \\
\hline & $\begin{array}{l}\text { Infected } \\
\text { carcasses }\end{array}$ \\
\hline & Hunters \\
\hline & Ornithodoros \\
\hline & $\begin{array}{l}\text { International } \\
\text { transport }\end{array}$ \\
\hline & Wild boar \\
\hline & Backyard pigs \\
\hline & Free range pigs \\
\hline 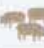 & Pig farms \\
\hline
\end{tabular}

provided for them by hunters. Once ASFV enters the wild boar population it spreads rapidly thanks to active social interactions leading to localized epidemics (from November to February) where most of the wild boar population dies.

Another potential mechanism of virus persistence occurs through animals scavenging on wild boar carcasses in spring, since ASFV may be able to survive in those carcasses during the cold period between the two seasonal incidence peaks. In addition, transmission through direct contact with infected free-ranging pigs cannot be ruled out where free ranging occurs.

Wild boar are capable of sustaining limited transmission for several months when there is a high population density and favourable timing for virus introduction (rut or reproduction periods, snow and subzero temperatures, etc.). Nonetheless, an independent year-round ASF transmission cycle in wild boar is most likely not yet established. However, there are some seasonal disease flare-ups during the rut period (November to January, when males actively move from one female group to another) and after the farrowing (May to June, when population reaches its seasonal maximum), which suggests that a year-round transmission cycle could be established if the virus survived through spring and passed to the next generation. With the current high mortality rates (i.e. most affected wild boar die), it is unlikely that wild boar can act as a suitable reservoir. In fact, wild boar seem to act as sentinels for unreported ASFV circulation in the LB pig production sector. In wild boar, incidence of ASF is lowest in October (2.5 percent), prior to onset of the rut period, and in March (5.0 percent), when population is at its minimum. These statistics reflect the effects of social interactions and population density dynamics in ASF incidence.

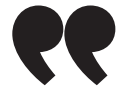

USUALLY, INFECTION BEGINS WHEN WILD BOAR POPULATIONS SCAVENGE ON ILLEGALLY DISPOSED ASFINFECTED PIG CARCASSES FROM THE DOMESTIC SECTOR.

\section{Challenges in ASF detection and control}

The short viremia and high mortality associated with ASF make it virtually impossible to detect the disease through active surveillance. For this reason, disease detection relies strongly on passive surveillance. An effective passive surveillance requires the trust of pig owners that report the disease to the veterinary authorities, a rapid laboratory diagnosis and a sound compensation strategy. Due to the existence of confounding diseases such as classical swine fever (CSF), clinical diagnosis needs to be confirmed in a laboratory. ASF does not transmit that rapidly from pig to pig, so changes in mortality rates at the large commercial farms are not necessarily evident enough to signal ASF arrival to the herd. Also, unusual clinical presentations may mislead the diagnosis, especially if the disease is new and unexpected in the region. All of these factors suggest that timely detection of new ASF introductions in whichever sector is tricky and, most often, significantly delayed. In 2009 to 2011, an average of 4.6 days and up to 11 days (Dudnikov et al., 2011) passed from the first sign of disease (usually indicated by death) before the ASF diagnosis was confirmed. This delay allows for unnoticed ASF spread, slaughter of infected animals and transportation of contaminated products outside the outbreak site, sometimes to long distances. Implementation of quarantine restrictions and other disease control measures are even more delayed from the time of diagnosis, mainly due to the high associated economic costs. Although a ban on movements of all agricultural products out of the ASF-affected area has to be immediately introduced according to legislation in the Russian Federation, local authorities and stockholders are very reluctant to invoke this measure without sufficient evidence, and decisions sometimes take weeks and months. One important lesson 
Figure 7. Densities of wild boar in Europe.

Data: various statistical data 2005-2011, FAO/EMPRES.

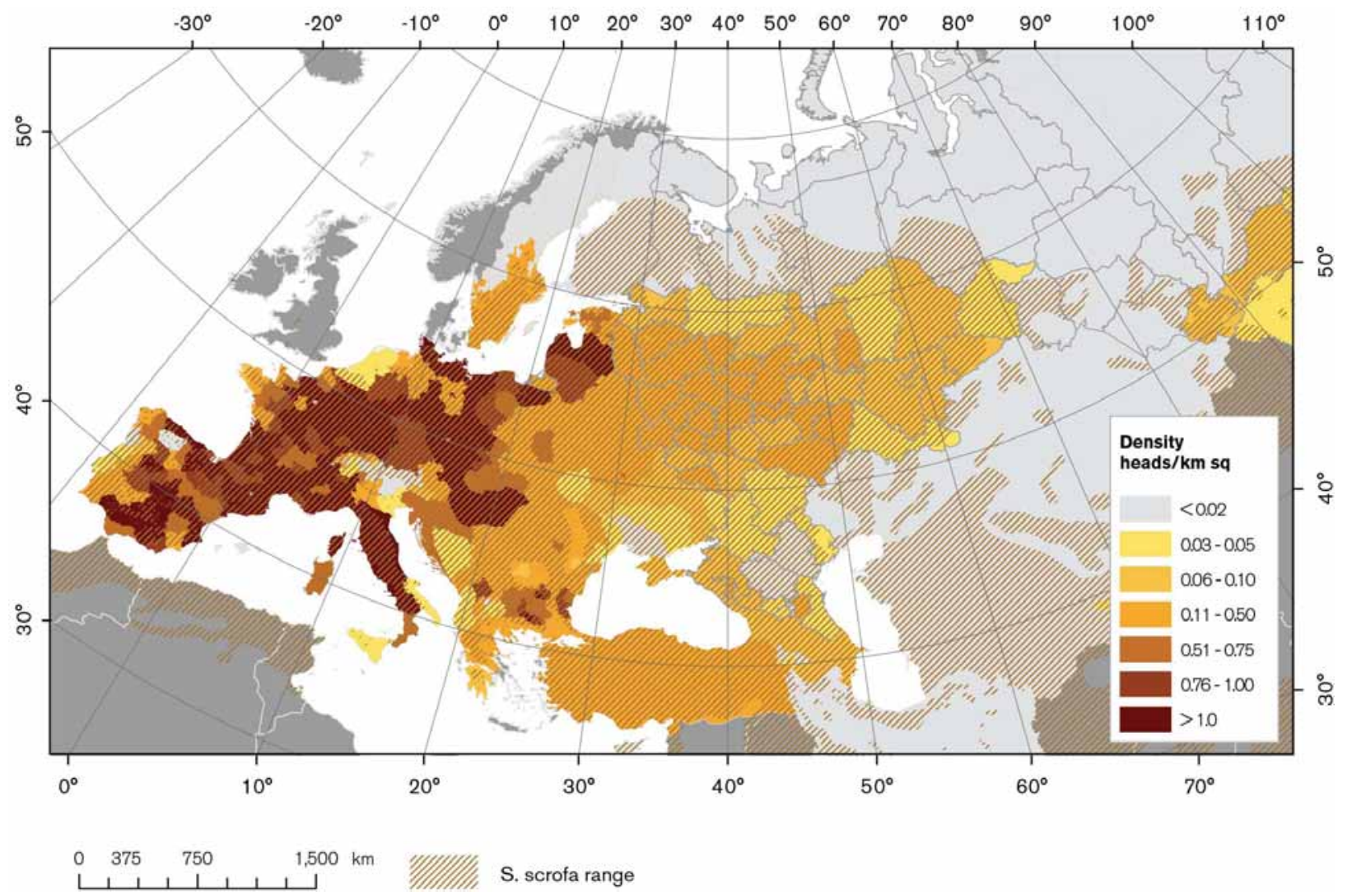

Figure 8. Densities of domestic pigs in the low biosecurity sector in Europe.

Data: various statistical data 2008-2011, FAO/EMPRES.

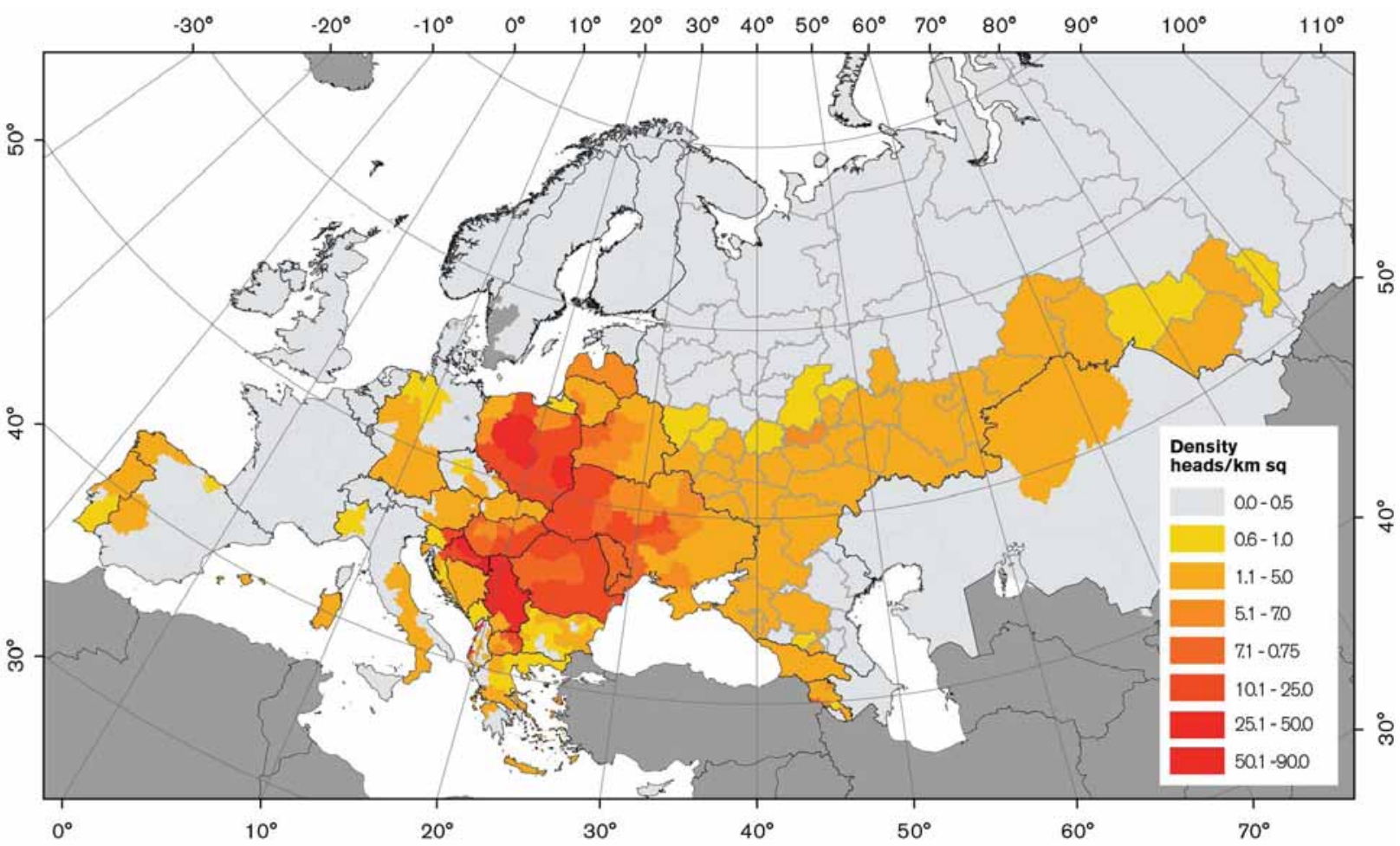

O $375750 \quad 1,500 \mathrm{~km}$ 
learned from this epidemiological study is the fact that disease control measures have to account for the distinct seasonality of ASF. It is clear that the main risk periods for its introduction and spread are summer and fall months for domestic pigs, and spring and winter months for wild boar.

\section{Risk assessment for the region}

Given the current unfavourable ASF dynamics (Rosselkhoznadzor, 2012) and recent predictions (Dudnikov et al., 2011), the odds of rapid eradication of the disease from the Russian Federation are poor. ASF will likely continue to threaten the food security of the whole of Eastern Europe for years, if not decades, to come. Countries in the region, particularly those that border the Russian Federation, must prepare for a long-term defense of their pig production systems from potential ASF incursions.

Both spatial and seasonal patterns of ASF incidence in the Russian Federation suggest that pig density in the LB sector is the leading factor in sustaining disease transmission. For this reason, those countries bordering the Russian Federation with LB-dominated pig production systems are the most vulnerable to ASF introduction and establishment. Those countries most at risk are Republic of Moldova, Kazakhstan, Ukraine and Latvia, with 55-83 percent of pigs in the LB sector (Table 1) and, to a lesser extent, Lithuania, Belarus and Estonia, with predominantly industrial pig production systems and only 9-27 percent of their pigs in LB systems. All ex-USSR countries have strong economic and cultural links with each other and share porous borders (in terms of veterinary contro of private goods), in particular Belarus and Kazakhstan, which are a part of the Customs Union with the Russian Federation. All these countries should be given the highest priority for investment in disease prevention.

PP

COUNTRIES BORDERING THE Russian Federation With LoW BIOSECURITY-DOMINATED PIG

PRODUCTION SYSTEMS ARE THE MOST VULNERABLE TO ASF INTRODUCTION.

In terms of ASF establishment after introduction into a new area, pig and wild boar population mapping done by EMPRES and risk maps (based on Gulenkin et al., 2011; map not shown here) suggest that the potential ASF agro-ecological niche, i.e. the LB pig production systems in Europe, is fairly extensive (Fig. 8). The model classified much of Eastern Europe as a medium to high ASF establishment risk area based on pig densities and production systems, road network density and other risk factors identified in southern Russian Federation. Provided with a similar epidemiological cycle and under similar disease control interventions after introduction (which may not necessarily hold true), the Balkan States, southeast Germany, Republic of Moldova, western Ukraine and Romania are at the highest risk of becoming enzootic. Since other factors may start playing an important role in the disease dynamics as ASFV colonizes new areas, it is difficult to predict the virus introduction paths to specific countries and its evolution.

In countries where the density of wild boar is higher than in the Russian Federation, i.e. Belarus, Estonia, Latvia, Lithuania and Ukraine (Table 1 and Fig. 7), the epidemiological role of wild boar may differ from what has been observed so far in the Russian Federation. A higher involvement of wild boar in the transmission cycle can be expected, and perhaps even a continuous (year-round) transmission cycle. Although wild boar comprise only 1.9 percent of the susceptible population in the region at risk (Table 1), their wild and free-living nature makes prevention and control in those populations particularly challenging.

The potential role of Ornithodoros ticks has not been taken into account in this assessment. The distribution and density of the different Ornithodoros tick species, whether they feed on pigs or wild boar, and their ability to transmit ASFV within the tick population and to suids are all largely unknown. Only some old publications on the subject are available for the region (Galuzo, 1957; Filippova, 1966), but Ornithodoros ticks are known to be present in the southern latitudes of the ex-USSR. There is an urgent need for more research in those areas.

There is no reason to expect that the mechanisms and routes of possible ASF introduction to the countries at risk will be different from what has been observed in the Russian Federation. Movement of infected meat that is then swill-fed to pigs is the most likely introduction route, not just into the Russian Federation's neighboring countries, but also much further, as was proven in July 2012 in Ukraine (Dietze et al., 2012). However, one cannot ignore the possibility of wild boar carrying the ASFV across borders. This route was how ASFV spread from Georgia into the Russian Federation (Chechen Republic).

Table 1. Total population and density of domestic pigs and wild boar in the countries already affected by ASF and in those that are not, but share borders with the Russian Federation. Countries are ordered by the prevalence of low biosecurity pig production sector in the population. Data: (FAO/EMPRES: 2000-2011).

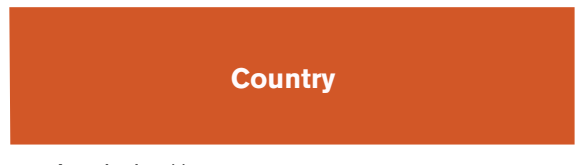

\begin{tabular}{lll} 
Population & $\%$ LB & $\begin{array}{l}\text { \% LB Pig density } \\
\text { (heads/km sq) }\end{array}$ \\
\hline 5300 & 100 & 0.05 \\
\hline 176100 & 97.2 & 2.45 \\
\hline 113688 & 84.9 & $3.7(0.6-9.1)$ \\
\hline 342000 & 83.3 & 8.4 \\
\hline 1343864 & 83 & $0.6(0.001-2.2)$ \\
\hline 8183842 & 56.1 & $8.8(3.0-25.0)$ \\
\hline 820286 & 54.5 & 6.9 \\
\hline 17640570 & 37.6 & $1.2(0-5.6)$ \\
\hline 1010681 & 27.2 & $4.6(1.7-9.9)$ \\
\hline 3910900 & 25.2 & $5.0(2.8-7.4)$ \\
\hline 392385 & 8.8 & 0.8 \\
\hline 1448440 & 0.4 & $0.03(0-0.1)$ \\
\hline $\mathbf{1 0 ~ 9 8 4 ~ 7 2 0}$ & $\mathbf{4 1 . 4}$ & $\mathbf{2 . 7 ( 0 - 2 5 . 0 )}$ \\
\hline
\end{tabular}

\begin{tabular}{ll} 
Population & Wild boar \\
& Density (heads/km sq)* \\
\hline 7500 & 0.087 \\
\hline 5000 & 0.072 \\
\hline 1080 & $0.037(0.003-0.068)$ \\
\hline 5000 & 0.148 \\
\hline 17564 & 0.006 \\
\hline 48982 & $0.118(0.014-0.704)$ \\
\hline 67200 & 1.039 \\
\hline 404570 & $0.082(0-0.435)$ \\
\hline 54608 & 0.84 \\
\hline 56001 & $0.267(0.211-0.358)$ \\
\hline 22650 & $0.511(0.318-0.651)$ \\
\hline 400 & 0.001 \\
\hline 690155 & $\mathbf{0 . 1 4 8 ( 0 - 1 . 0 3 9 )}$ \\
\hline
\end{tabular}

\begin{tabular}{l} 
Azerbajan $^{\star \star}$ \\
\hline Georgia $^{\star \star}$ \\
\hline Armenia $^{\star \star}$ \\
\hline Moldova \\
\hline Kazakhstan \\
\hline Ukraine \\
\hline Latvia \\
\hline Russian Federation \\
\hline Lithuania \\
\hline Belarus \\
\hline Estonia \\
\hline Finland \\
\hline Grand total \\
\hline
\end{tabular}

* when available, the range of density variation at the subnational level is provided in parenthesis.

${ }^{\star *}$ countries already affected by ASF 


\section{A focus on Ukraine}

Ukraine, with its 32 percent rural population and 8.2 million pigs (of which 56.1 percent are under LB conditions), is the key country in terms of preventing further westward expansion of ASF (Beltrán-Alcrudo et al. 2010). Luckily, in the area of eastern Ukraine that borders the Russian Federation, the proportion of rural population is low and most of the pig production concentrates in specialized farms (Fig. 9; FAO, 2010). However, there is a strong and gradual westward increase in LB pig production at the Oblast level, both in terms of proportion and density (Fig. 9). This pattern implies that ASF control would be much more difficult if it arrived at the central and western parts of the country, which are dominated by the LB pig production sector. This control would be further complicated if wild boar (Fig. 9) or ticks became involved. Measures undertaken by the Ukrainian veterinary authorities following the July 2012 outbreak were sufficient to limit any further spread of ASF, but with the unfavourable disease dynamics in the Russian Federation, similar introductions into the country are expected.

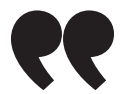

THE EXTENSIVE LEGAL AND ILLEGAL MOVEMENT OF PEOPLE ACROSS BORDERS NEEDS TO BE SERIOUSLY

TAKEN INTO ACCOUNT, I.E. LABOUR MIGRANTS, TOURISTS, REFUGEES AND DISPLACED PEOPLE.

Ukraine's porous $2295 \mathrm{~km}$ border with the Russian Federation allows for movement of potentially infected material. It is very challenging to prevent infected meat entering the country through the 43 main RussianUkrainian border control posts (26 roads, 16 railways and 1 ferry), and 21 local control posts, crossed only on foot by the people who live close to the border (State Border Guard Service of Ukraine, http://www.dpsu. gov.ua). The maritime border (321 km) between Russia and Ukraine in the Azov Sea has not been delineated, thus posing an additional challenge for the control of movement and smuggling of goods across the sea. Also, the extensive legal and illegal movement of people across borders needs to be seriously taken into account, i.e. labour migrants, tourists, refugees and displaced people. For example, Ukraine alone exports unofficially an estimated 2 to 7 million temporary workers to the Russian Federation and the EU Member States. Other estimates by Markov et al. (2009) put this figure at 4.5 million, of which 2 million work in Russia and 1.7 million in the EU. These millions of people carry the cheapest locally available food every time they travel between these countries and they regularly receive parcels with foodstuffs from home.

\section{Risk management options for at-risk countries}

It is particularly important that ASF-free areas remain free by preventing the introduction of the disease and by swiftly responding to it when it occurs. All applicable control and eradication measures are based on classical disease control methods, including surveillance, epidemiological investigation, tracing and stamping out of infected herds. They are to be combined with strict quarantine and biosecurity measures (particularly in relation to swill-feeding) and animal movement control. More details can be found in Beltrán-Alcrudo et al. (2009) and FAO/OIE/World Bank (2010). Specific issues that need to be analysed more carefully, based on the lessons learned from the Russian Federation, include the following:

\section{Prevention and early detection}

- Raising awareness is critical at all levels. The current scenario in the Russian Federation suggests that it should be particularly stressed at the often informal backyard level and should involve not just the pig keepers, but all actors along the whole value chain, i.e. butchers, middlemen, slaughter houses, etc. They need to be aware of how to prevent and recognize the disease, and must understand the importance of reporting outbreaks to the national authorities. Their cooperation in reporting is the only way to detect outbreaks promptly.

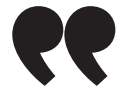

ALL ACTORS ALONG THE BACKYARD PIg VALUE CHAIN NEED TO BE AWARE OF HOW TO PREVENT AND

RECOGNIZE THE DISEASE, AND THEY MUST UNDERSTAND THE IMPORTANCE OF REPORTING OUTBREAKS TO THE NATIONAL AUTHORITIES.
- Biosecurity should also carefully address the issue of the LB sector, which is characterized by poor biosecurity. Freerange pig production practices pose additional challenges as such systems defy all biosecurity principles. A deeply entrenched tradition, free-ranging allows the raising of pigs with almost no feed inputs. Therefore, enforcing pig enclosure would go against the purpose of free-ranging and would be difficult to implement. Similarly, swill feeding provides a cheap (sometimes free) feed source for the pigs, so its effective banning is not easily achievable. Alternative, viable solutions would be awareness campaigns that encourage producers not to use pork or other pig byproducts and to boil the swill prior to use.

- Wild boar involvement in ASF transmission represents an additional challenge. It is important to ensure that hunters are well informed of the disease and aware of the importance of reporting sick or dead wild boar. Also, passive wild boar surveillance along the borders with infected areas will allow for the early detection of the disease.

- Large numbers of temporary workers, diaspora, tourists and inhabitants near border areas who live or travel to ASFinfected countries, represent the largest risk of introduction of the disease.

These people carry with them (or mail) potentially infected pork products.

Awareness of the general population, but particularly of these groups, will be key to minimizing ASF introductions. Posters, leaflets and other awareness materials, particularly at the borders and other ports of entry are powerful prevention tools, as are strict border controls, sanctions and fines.

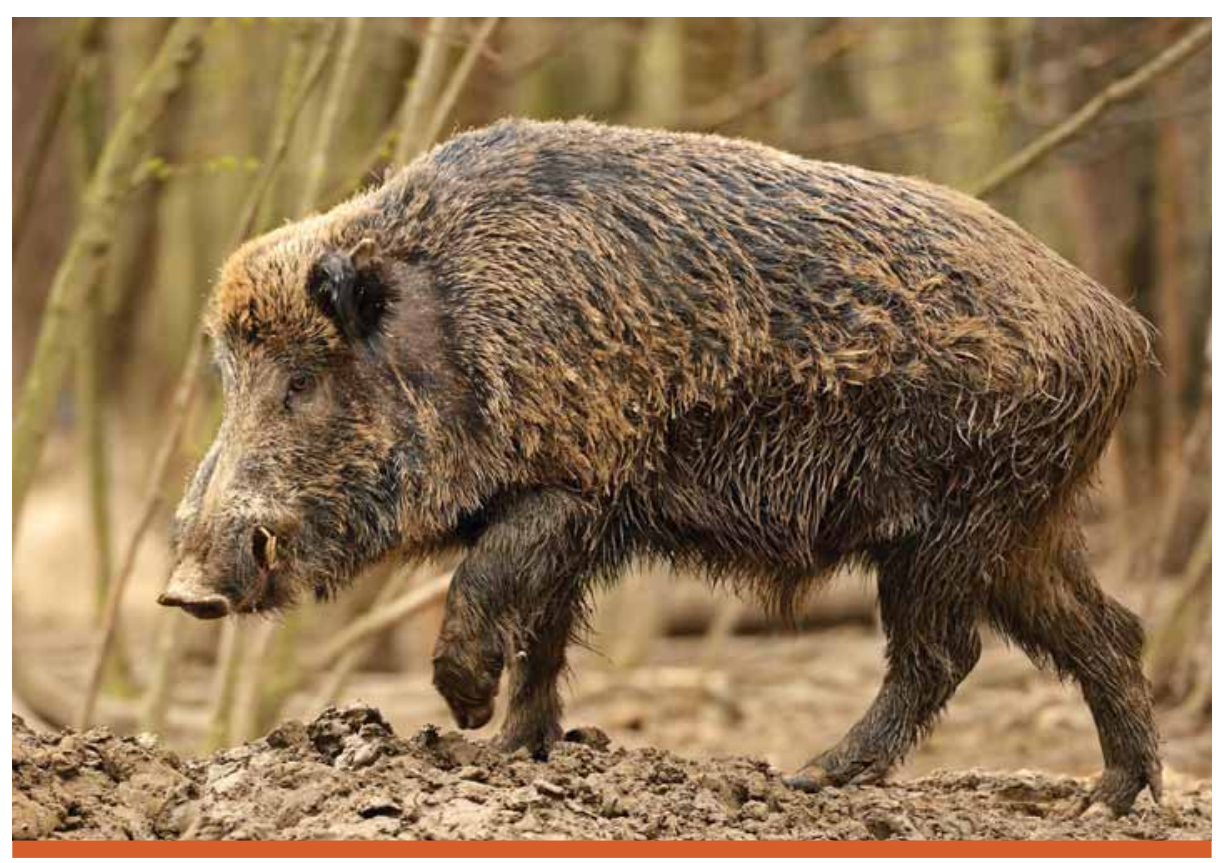


Figure 9. Distribution of ASF-susceptible populations and location of the most recent virus introduction in Ukraine in 2012.

Left side, top to bottom: density of pigs in the LB sector (2011); density and numbers of wild boar (2007); and density of pigs in the HB sector (2011) by Oblast. Figures are population estimates (thousands). Right side, top to bottom: density of pigs at the resolution of the second administrative division level in eastern Ukraine in the LB sector with $150 \mathrm{~km}$ risk zone and in the HB sector with border control posts. The two right side maps include the districts and municipalities of Sumy, Kharkiv, Luhansk, Donetzk, Zaporizhzhya and Crimea Autonomous Republic. Data: National Authorities, 2010. Note that all classification schemes on the maps are different.
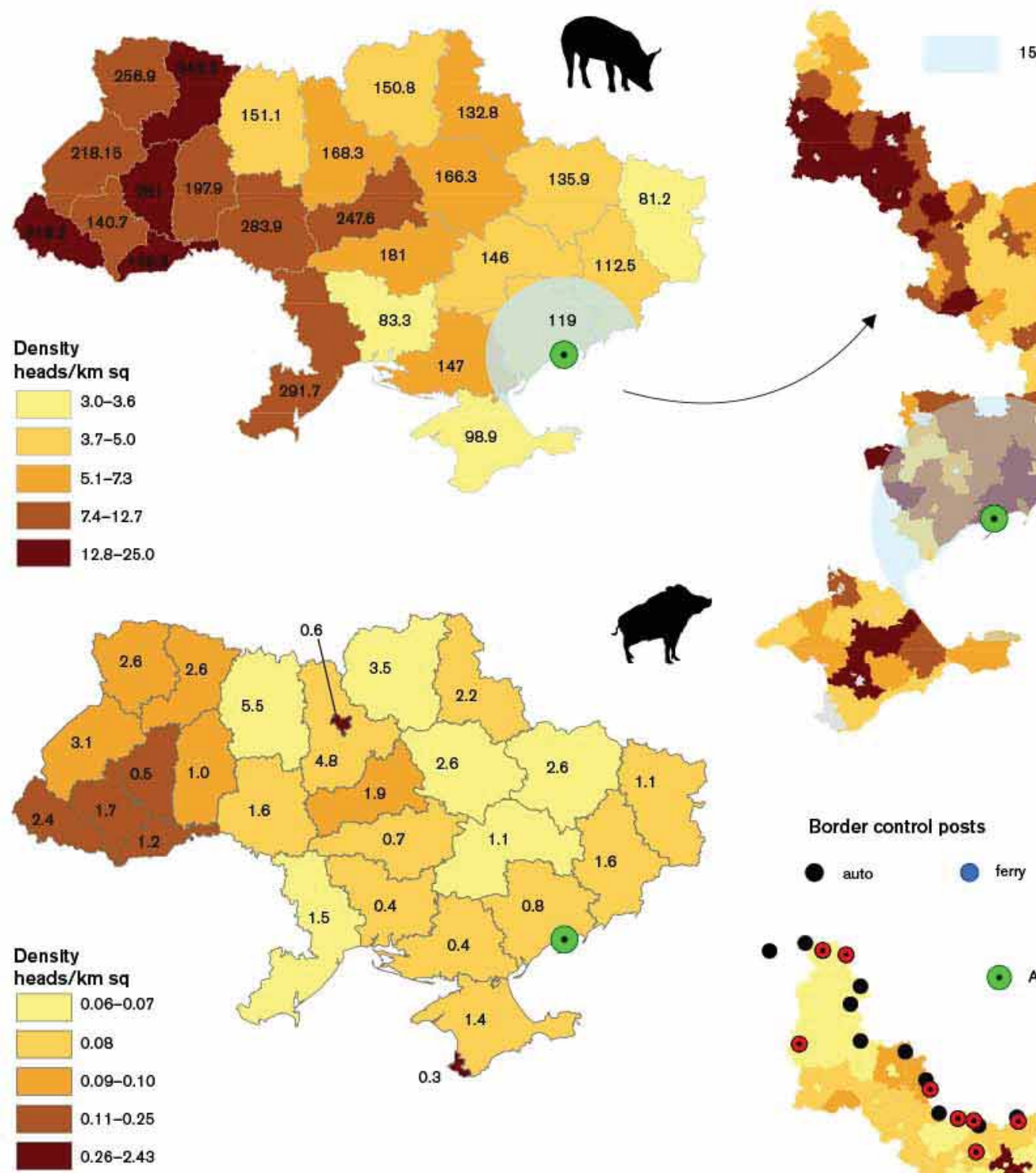

Density

heads/km sq

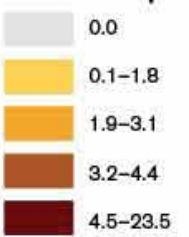

Border control posts
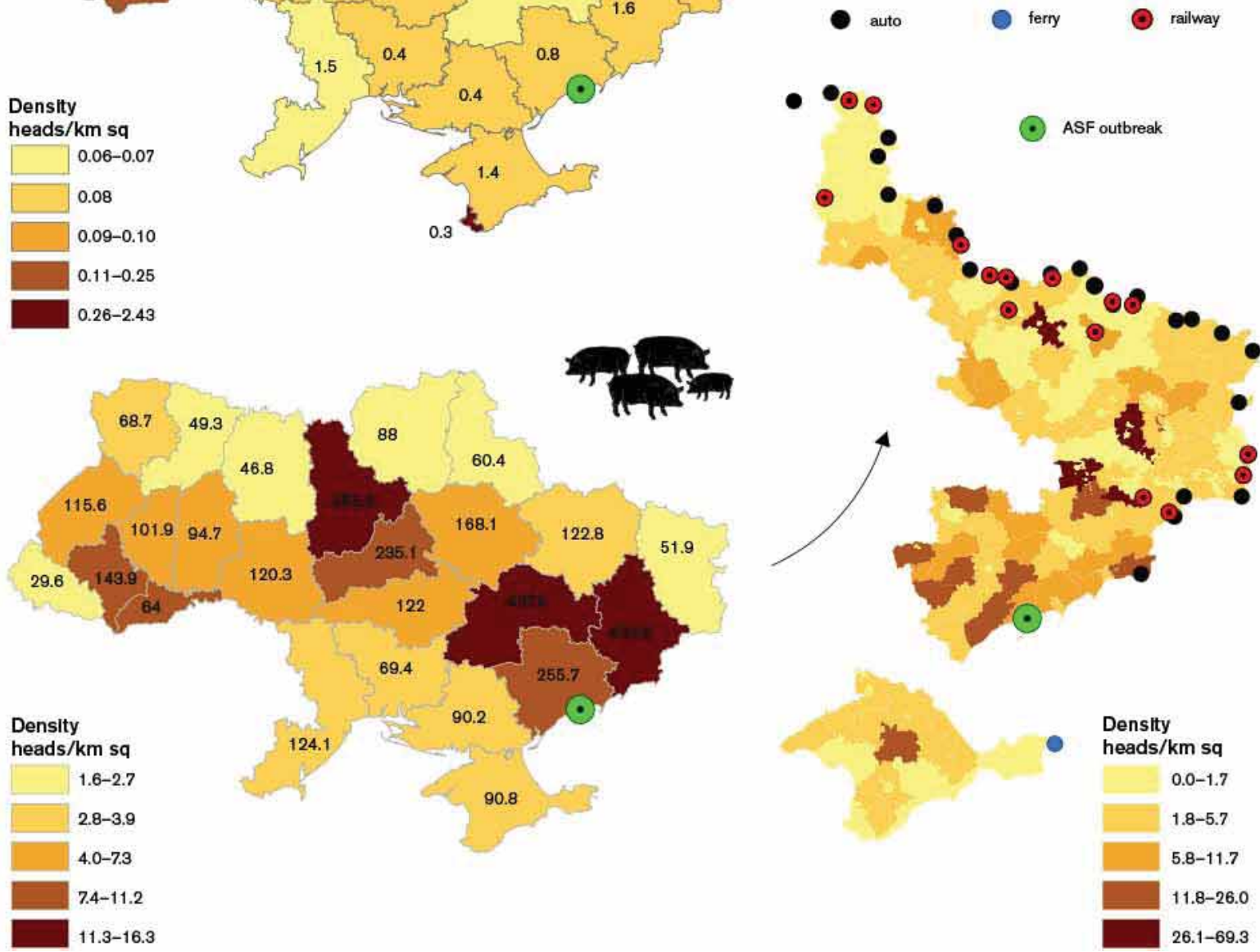


\section{Preparedness and control of the first ASF introductions}

- Detailed information on pig and wild boar distribution patterns arranged into databases (pig farm registers, backyard holding surveys, mapping of wild boar population and feeding locations, etc.) greatly helps to evaluate risks, to estimate resource allocations or economical losses, to assess the epidemiological situation and to better plan disease control measures.

- In terms of preparedness, it is key to plan in advance how to deal with ASF in wild boar, by creating the necessary links with the government agency that deals with wild boar, and with hunters (possibly through hunter's associations).

- Have a thorough understanding of the backyard sector to better predict the special and seasonal pattern of the disease, to identify the actors and the most vulnerable points along the pig and pork market chains, and to develop realistic prevention and control measures for LB settings.

- The first hours that follow an outbreak are critical and the swift implementation of control measures following an outbreak is often the only way to contain the disease. Containment requires quick resource mobilization, swift information flow and precise distribution of responsibilities, which are clearly described in the outbreak response plans.

- For stamping out to be effective, it must be linked to proper and timely compensation. In the absence of a fair and timely compensation plan, the implementation of stamping out will encounter a strong opposition from the farming community. Without an economic incentive, when confronted to an outbreak, farmers will slaughter the infected animals (and sell the meat) or illegally dispose of the carcasses rather than reporting these outbreaks to the national authorities. It is also important to ensure that the culling of animals is done in a humane way.

PP

FOR STAMPING OUT TO BE EFFECTIVE, IT MUST BE LINKED TO PROPER AND TIMELY

\section{COMPENSATION.}

- ASF prevention and control in wild boar is a complicated and potentially polemic issue that requires careful consideration. Preventive population control (before the virus enters the population) can be applied to reduce risk of wild boar involvement when densities are too high. It requires proper evaluation by wildlife professionals (kill rates and hunting pressure, seasons and demographic groups targeted). Emergency population control, i.e. wild boar depopulation after ASF introduction, is likely to be counterproductive and can lead to the dispersal of infected individuals. On the other hand, suspension of supplementary feeding of animals could help reduce contact and virus transmission rates.

\section{Conclusions}

Since 2008, ASF persists endemically and continues to spread into new areas of the Russian Federation. Half of the 30 affected administrative units are either endemic or on the way to becoming endemic, including Tverskaya Oblast, where some of the highest wild boar densities are found. The analysis of outbreak data from the Russian Federation in this study, provides valuable lessons for atrisk countries in the region and beyond.

In the Russian Federation, the high-risk periods for disease introduction and spread are summer and fall for domestic pigs, and the end of spring and winter for wild boar. The LB sector remains the main risk factor for disease introduction and endemicity, almost exclusively through swill-feeding of infected pork. The long resistance of ASFV in pork and other pig products represent the main reservoir of the disease. In the absence of adequate control measures, LB production systems can sustain ASF transmission indefinitely, seasonally leaking to higher biosecurity sectors, i.e. semi-commercial and even industrial pig farms. Timely detection of ASF can be complicated and often delayed, thus allowing further spread through the movement of pig products within, and often outside, the affected region. ASF also spills easily from LB systems to wild boar, usually through the illegal disposal of contaminated carcasses into the environment. So far, circulation of ASF observed in wild boar populations has been limited in space and time. However, the role of wild boar could change into a year-round transmission cycle, should denser populations be affected. In addition, the role of wild boar in transboundary spread cannot be neglected.

The worsening of the epidemic in the Russian Federation, with an increased ASFV load and circulation and the establishment of the disease in central European Russia, imply an exponential increase in the risk of ASF to further expand westwards through the increasingly dense populations of LB pig and wild boar populations into Eastern Europe and beyond. Countries bordering the Russian Federation with large LB pig populations, particularly Ukraine, Republic of Moldova, Kazakhstan and Latvia are most vulnerable to ASF introduction and endemic establishment. At-risk countries should be on high alert and should learn from the Russian experience, investing in ASF preparedness and improving their early detection and response capacity. Sporadic introductions are bound to occur, so a swift response to outbreaks to prevent further spread is critical.

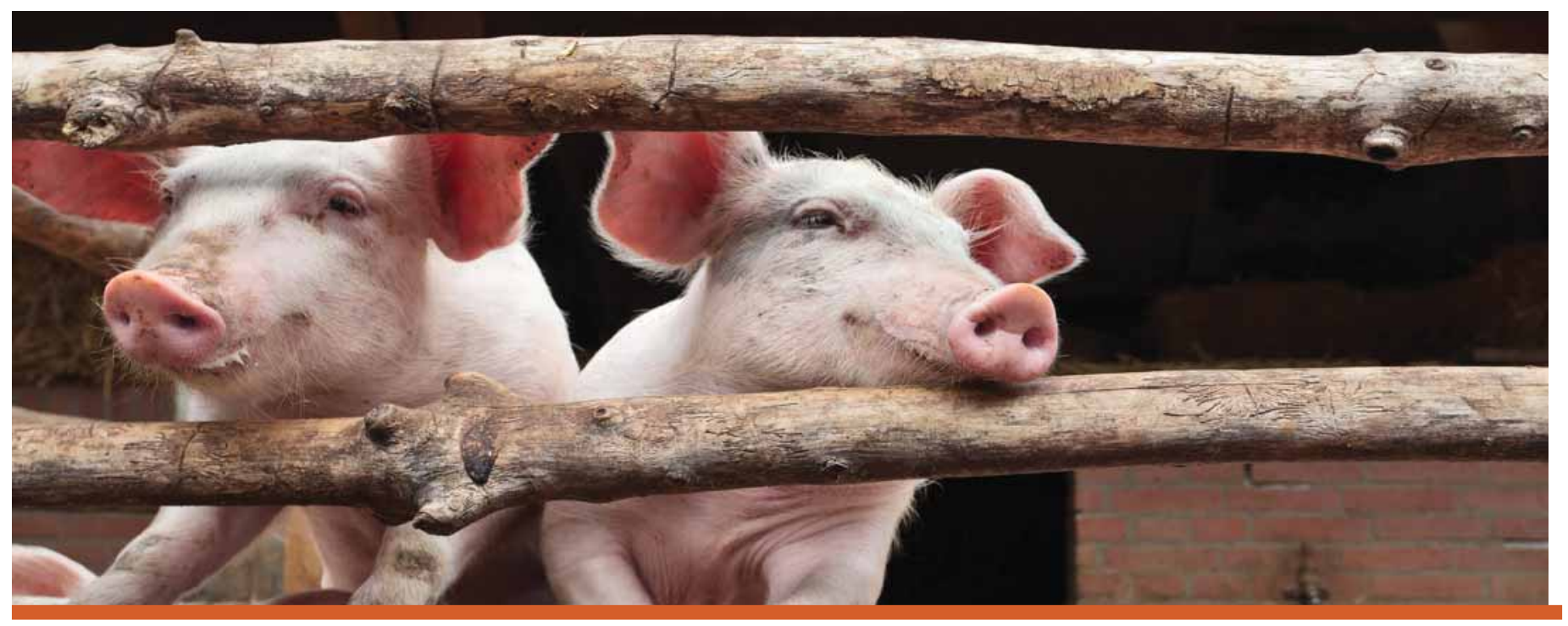




\section{References}

Anonymous. 2012. About a meeting of the Collegium of the Federal Service for Veterinary and Phytosanitary Surveillance (in Russian) (available at http://www. fsvps.ru/fsvps/news/5123.html)

Beltrán-Alcrudo, D., Guberti, V., de Simone, L., De Castro, J., Rozstalnyy, A., Dietze, K., Wainwright, S. \& Slingenbergh, J. 2009. African swine fever spread in the Russian Federation and the risk for the region. EMPRES Watch. Rome, FAO (available at ftp://ftp.fao.org/docrep/fao/012/ak718e/ak718e00. pdf).

Beltrán-Alcrudo, D., Lubroth, J., Depner, K. \& De La Rocque, S. 2008. African swine fever in the Caucasus. EMPRES Watch. Rome, FAO (available at ftp://ftp.fao.org/docrep/fao/011/aj214e/aj214e00.pdf).

Beltrán-Alcrudo, D., Khomenko, S. \& Dietze, K. 2010. FAO takes a close look at the threat of African swine fever introduction into Eastern Europe, specifically Ukraine. EMPRES Transboundary Animal Diseases Bulletin 36: 2-17. Rome, FAO (available at http://www.fao.org/docrep/013/i1958e/ i1958e00.pdf).

Chapman, D.A.G., Darby, A.C., Da Silva, M., Upton, C., Radford, A.D. \& Dixon, L.K. 2011. Genomic analysis of highly virulent Georgia 2007/1 isolate of African swine fever virus. Emerg Infect Dis, 17(4) April (available at http://dx/doi. org/10.3201/eid1704.101283)

Danilkin, A.A. 2002. Pigs (Suidae). Mammals of Russia and the adjacent areas. Moscow, GEOS. 309 pp. (in Russian).

Dietze, K., Beltrán-Alcrudo, D., Khomenko, S., Seck, B., Pinto, J., Diallo, A., Lamien, C., Lubroth, J. \& Martin, V. 2012. African Swine Fever (ASF) Recent developments - timely updates. Focus on No. 6. Rome, FAO. (available at http://www.fao.org/docrep/016/ap372e/ap372e.pdf).

Dudnikov, S.A., Petrova, O.N., Oganesyan, A.G., Gulenkin, V.M., Bardina, N.S., Erastova, E.E., Dudorova, M.V. \& Karaulov, A.K. 2011. [A forecast for African Swine Fever in the Russian Federation in 2012] Vladimir. 36 pp. (in Russian) (available at http://www.fsvps.ru/fsvps-docs/ru/iac/publications/ iac_public24.pdf)

FAO. 2010. FAO takes a close look at the pig sector in Eastern Europe to better understand the threats of African swine fever. EMPRES Watch. Rome, FAO (available at www.fao.org/docrep/012/ak755e/ak755e00.pdf).

Food and Agricultural Organization of the United Nations/World Organisation for Animal Health/World Bank. 2010. Good practices for biosecurity in the pig sector - Issues and options in developing and transition countries. FAO Animal Production and Health Paper No. 169. Rome, FAO (available at http://www.fao.org/docrep/012/i1435e/i1435e00.pdf)

Filippova, N.A. 1966. [Argasid ticks (Argasidae)]. Fauna SSSR, Paukoobraznye 4(3). Leningrad, Nauka, 256 pp. (in Russian).

FSSS. 2009. [Livestock statistics for the year 2009]. Federal State Statistics Service of the Russian Federation (in Russian) (available at http://www.gks.ru).

Galuzo, I.G. 1957. [Argasid ticks and their epizootologic significance]. AlmaAta, 129 pp. (in Russian).

Gulenkin, V.M., Korennoy, F.I., Karaulov, A.K. \& Dudnikov, S.A. 2011. Cartographical analysis of African swine fever outbreaks in the territory of the Russian Federation and computer modeling of the basic reproduction ratio. Preventive Veterinary Medicine, 102(3) 1 December 2011: 167-174 (available at http://www.sciencedirect.com/science/article/pii/S0167587711002303).
Markov, I., Ivankova-Stetsyuk, O. \& Seleshchuk, H. 2009. Ukrainian Labor Migration in Europe. In I. Markov, ed. Findings of the complex research of Ukrainian labor immigration processes. Lviv, 72 pp. (available at http://www.kievdialogue.org/fileadmin/user_upload/KG_8_2012/0172_Markov_Caritas-1_01. pdf).

Oliver, W.L.R., Brisbin, I.L.Jr. \& Takahashi, J. 1993. The Eurasian wild pig (Sus scrofa). In W.L.R. Oliver, ed. Pigs, peccaries and hippos: status survey and action plan, pp. 112-121. Gland, Switzerland, IUCN.

Putman, R., Apollonio, M. \& Andersen, R. eds. 2011. Ungulate management in Europe: problems and practices. Cambridge, Cambridge University Press, 410 pp. (available at http://books.google.bg/books?id=02zA9jJT8wC\&hl=cs\&sitesec=reviews).

Rahimi, P., Sohrabi, A., Ashrafihelan, J., Edalat, R., Alamdar, M., Masoudi, M., Mastofi, S. \& Azadmanesh, K. 2010. Emergence of African swine fever virus, Northwestern Iran. Emerg Infect Dis, 16(12): 1946-1948.

Rosselkhoznadzor. 2012. (available at http://www.fsvps.ru/fsvps/iac/asf.html).

Saulich, M.I. 2007. Area of distribution and damage of Sus scrofa Linnaeus. Interactive Agricultural Ecological Atlas of Russia and Neighboring Countries (available at http://www.agroatlas.ru/en/content/pests/Sus_scrofa/map/).

Sludskiy, A.A. 1956. [Wild boar (morphology, ecology, economic and epizootological role, harvesting)]. Alma-Ata, Former USSR, Izdatelstvo Akademii Nauk Kazkhskoi SSR. 220 pp. (in Russian).

Volodina, O.A. 2011. Wild Boar. In: State of the resources of game animals in the Russian Federation in 2008-2010. Information and analytical materials. Game animals of Russia (Biology, Conservation, Research into the State of Resources and their Sustainable Use). Issue 9. Moscow: Fizicheskaya Kultura, 2011. pp. 22-29 (in Russian) (available at www.mnr.gov.ru/upload/iblock/bf5/ ohota_resurses.doc) 


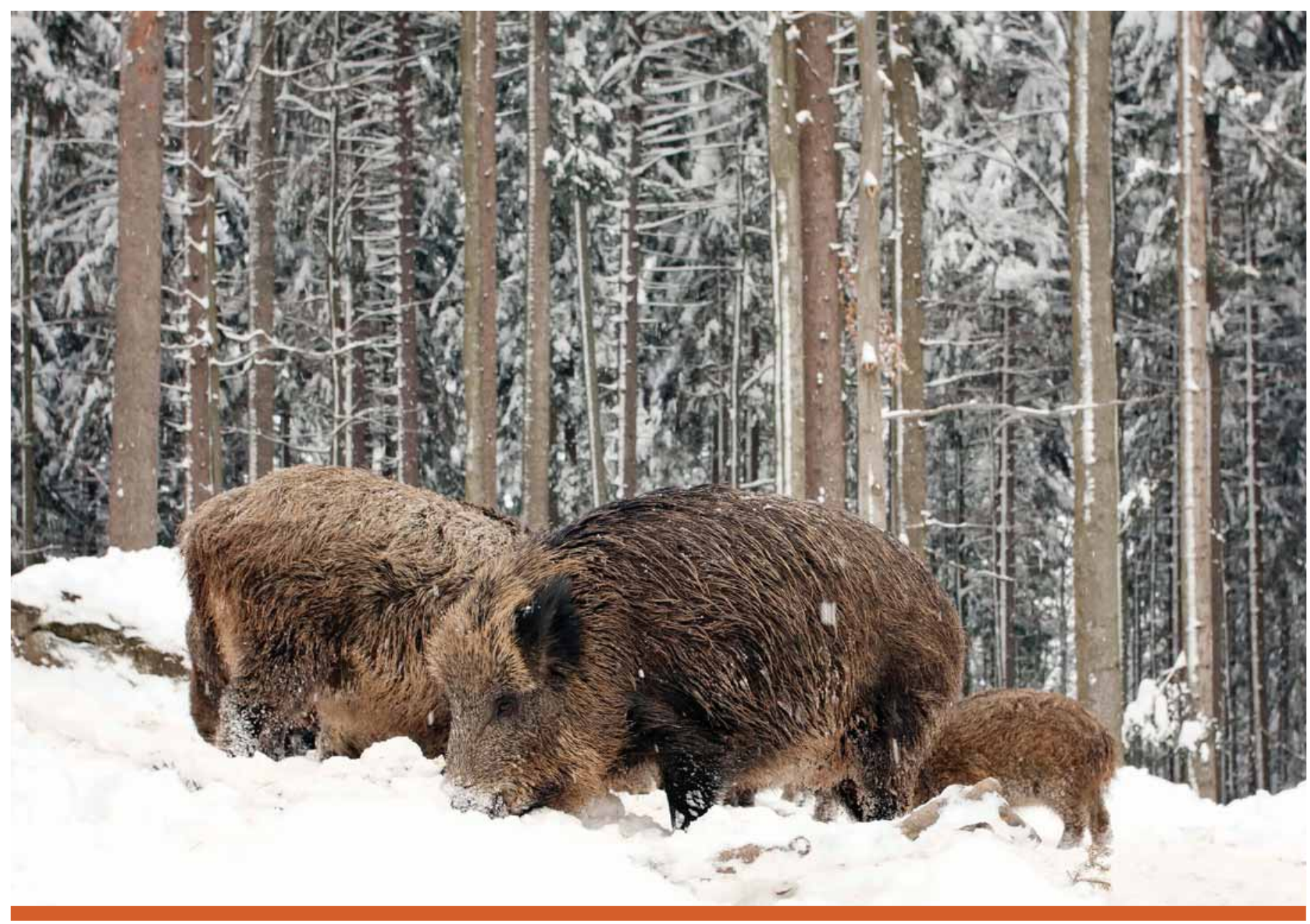

\section{CONTACT}

EMPRES Watch bulletins are an EMPRES-Animal Health alert communication product. The Emergency Prevention System (EMPRES) is an FAO programme, founded in 1994, with the goal of enhancing world food security, fighting transboundary animal and plant pests and diseases and reducing the adverse impact of food safety threats. EMPRES-Animal Health is the component dealing with the prevention and control of transboundary animal diseases (TADs).

To subscribe to this bulletin or to ask for information about EMPRES-Animal Health send an email to:

empres-livestock@fao.org or a fax to (+39) 0657053023

For more information visit us at http://www.fao.org/ag/empres.html

EMPRES-Animal Health can assist countries in the shipment of samples for TAD diagnostic testing at a FAO reference laboratory and reference centre. Please contact Empres-Shipping-Service@fao.org for information prior to sampling or shipment. Please note that sending samples out of a country requires an export permit from the Chief Veterinarian's Office of the country and an import permit from the receiving country.

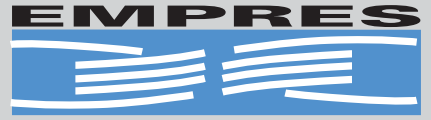

EMERGENCY PREVENTION SYSTEM

\section{Recommended citation}

FAO. 2013. African swine fever in the

Russian Federation: risk factors for Europe and beyond. EMPRES WATCH, Vol. 28, May 2013. Rome.

Cover Photo: (2010/Christian Martínez Kempin

\section{COPYRIGHT NOTICE AND DISCLAIMER}

The designations employed and the presentation of material in this information product do not imply the expression of any opinion whatsoever on the part of the Food and Agriculture Organization of the United Nations (FAO) concerning the legal or development status of any country, territory, city or area or of its authorities, or concerning the delimitation of its frontiers or boundaries. The mention of specific companies or products of manufacturers, whether or not these have been patented, does not imply that these have been endorsed or recommended by $F A O$ in preference to others of a similar nature that are not mentioned. The views expressed in this information product are those of the author(s) and do not necessarily reflect the views of FAO.

All rights reaserved. FAO encourages the reproduction and dissemination of material in this information product. Non-commercial uses will be authorized free of charge, upon request. Reproduction for resale or other commercial purposes, including educational purposes, may incur fees. Applications for permission to reproduce or disseminate FAO copyright materials, and all queries concerning rights and licences, should be addressed by e-mail to copyright@fao.org or to the Chief, Publishing Policy and Support Branch, Office of Knowledge Exchange, Research and Extension, FAO, Viale delle Terme di Caracalla, 00153 Rome, Italy. 